EDITORIAL

https: / /doi.org/10.22239/2317-269x.01950

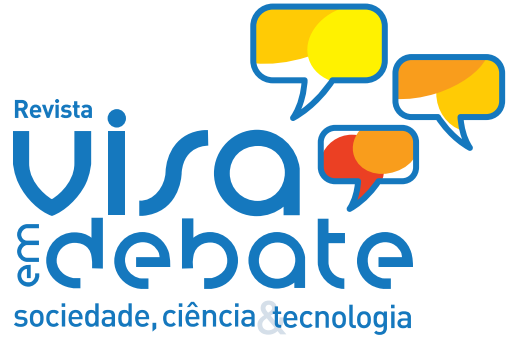

sociedade, ciência tecnologia

\title{
As doenças crônicas não transmissíveis e a COVID-19
}

\author{
Maria Helena Simões Villas \\ Bôas* (iD
}

Instituto Nacional de Controle de Qualidade em Saúde, Fundação Oswaldo Cruz (INCQS/Fiocruz), Rio de Janeiro, RJ, Brasil
Desde nosso último editorial, os números relacionados à COVID-19 no Brasil se aceleraram de forma descontrolada. 0 número de mortes praticamente dobrou, porém, a transmissão tem dado sinais de desaceleração, mesmo que ainda em níveis muito elevados. Vários pesquisadores têm alertado para os riscos associados da COVID-19 com as doenças crônicas não transmissíveis (diabetes, câncer, obesidade, hipertensão etc.), o que levou Horton ${ }^{1}$ a argumentar que não estamos diante de uma pandemia, e sim uma sindemia.

Sindemias são caracterizadas por um conjunto de problemas de saúde influenciado por interações biológicas, psicológicas e sociais que aumentam a suscetibilidade de um indivíduo e contribuem para a carga excessiva de doenças em uma população1.

É consenso que essa designação não pode levar em conta apenas o conceito tradicional saúde-doença, ela se reflete na interação entre um contexto social e ambiental caracterizado por uma profunda desigualdade social ${ }^{2}$.

A situação social e econômica da população brasileira, sem forma de subsistência sustentável devido à escassez de emprego e ao difícil acesso à saúde, em um sistema de saúde que sobrevive com recursos cada vez mais incipientes, poderá fazer surgir precocemente a terceira onda ("paciente invisível") de doença, composta por pacientes que foram negligenciados em tempos de COVID-19 portadores de condições crônicas (agudizadas ou não) e condições agudas não COVID-193,4.

A falta de atendimento a esses pacientes poderá levar a graves consequências econômicas e sociais, resultando em deficiências graves, mortes prematuras e progressivas perdas econômicas ${ }^{5}$.

Sem cuidados de proteção individuais e coletivos, nós não conseguiremos conter a disseminação do vírus, o que contribuirá mais ainda para a instalação de uma condição adversa em todos os níveis de atendimento à saúde.

É nesse contexto de profundo pesar por todas as vítimas atingidas pela COVID-19 que lançamos uma nova edição (maio de 2021) da revista Vigilância Sanitária em Debate: Sociedade, Ciência \& Tecnologia (Health Surveillance under Debate: Society, Science \& Technology) - Visa em Debate. Esta edição traz publicações com diversos conteúdos pertinentes à vigilância sanitária. Foram inseridos um debate, uma revisão, dois relatos de experiência e 15 artigos originais.

Algumas dessas publicações ressaltam a necessidade de a agência reguladora atuar na elaboração de normativas que possam regular o uso seguro de medicamentos oncológicos injetáveis, produtos fronteira, nanomedicamentos e a utilização de concentrados de plaqueta. Foi destacada também a relevância da rotulagem em produtos alimentícios como uma fonte de informações que apoie as escolhas do consumidor. Usando-se o medicamento talidomida, foi realizado um estudo sobre a farmacovigilância no Brasil. A conformidade normativa de produtos (sal para consumo humano) e estabelecimentos ligados à saúde (educação infantil, estúdios de tatuagem, embarcações mistas na Amazônia, food trucks) foi apresentada. A área de gestão está representada por duas publicações que discutem os regramentos e códigos sanitários das secretarias estaduais de saúde e o perfil de uma equipe de Vigilância Sanitária. A resistência microbiana foi abordada pela caracterização de infecções de sítio cirúrgico e cultura de vigilância. A produção de itens de ensaio de proficiência, usados para avaliar a competência de laboratórios de 
ensaio e calibração, e pouco disponíveis no Brasil, foi reportada. A avaliação da produção científica sobre o controle de qualidade de espécies vegetais presentes na lista da Relação Nacional de Medicamentos Essenciais (Rename) indicou a possibilidade de que esses estudos possam ser utilizados como referência na elaboração de monografias para a Farmacopeia Brasileira.

Boa leitura!

\section{REFERÊNCIAS}

1. Horton R. Offline: Covid-19 is not a pandemic. Lancet. 2020;296(10255):874. https://doi.org/10.1016/S0140-6736(20)32000-6

2. Porto MF. No meio da crise civilizatória tem uma pandemia: desvelando vulnerabilidades e potencialidades emancipatórias. Vigil Sanit Debate. 2020;8(3):2-10. https: / /doi.org/10.22239/2317-269x.01625

3. Lee TH. The invisible patient: caring for those without Covid-19. NEJM Catalyst. 27 abr 2020.

4. Mendes EV. O lado oculto de uma pandemia: a terceira onda da Covid-19 ou o paciente invisível. 2020[17 maio 2021]. Disponível em: https: / /www.conass.org.br/wp-content/ uploads/2020/12/Terceira-Onda.pdf

5. World Health Organization - WHO. The impact of the Covid-19 pandemic on noncommunicable disease resources and services: results of a rapid assessment. Geneva: World Health Organization; 2020[acesso 16 maio 2021]. Disponível em: https://apps.who.int/iris/bitstream/han dle/10665/334136/9789240010291-eng. pdf?sequence $=1$ \&isAllowed $=y$

Licença CC BY-NC atribuição não comercial. Com essa licença é permitido acessar, baixar (download), copiar, imprimir, compartilhar, reutilizar e distribuir os artigos, desde que para uso não comercial e com a citação da fonte, conferindo os devidos créditos de autoria e menção à Visa em Debate. Nesses casos, nenhuma permissão é necessária por parte dos autores ou dos editores. 